\title{
The impact of advanced biofuels on aviation emissions and operations in the U.S.
}

\author{
Niven Winchester, ${ }^{a,}{ }^{*}$ Robert Malina ${ }^{\mathrm{b}}$, Mark D. Staples ${ }^{\mathrm{b}}$ and Steven R.H. Barrett ${ }^{\mathrm{b}}$
}

\begin{abstract}
We analyze the economic and emissions impacts on U.S. commercial aviation of the Federal Aviation Administration's renewable jet fuel goal when met using advanced fermentation (AF) fuel. These fuels have recently been certified for use in aircraft and could potentially provide greater environmental benefits than aviation biofuels approved previously. Due to uncertainties in the commercialization of AF technologies, we consider a range of assumptions concerning capital costs, energy conversion efficiencies and product slates. In 2030, estimates of the implicit subsidy required to induce consumption of AF jet fuel range from $\$ 0.45$ to $\$ 20.85$ per gallon. In all cases, as renewable jet fuel represents around $1.4 \%$ of total fuel consumed by commercial aviation, the goal has a small impact on aviation operations and emissions relative to a case without the renewable jet fuel target, and emissions continue to grow relative to those in 2005 . Costs per metric ton of carbon dioxide equivalent abated by using biofuels range from $\$ 42$ to $\$ 652$.
\end{abstract}

JEL codes: C68, L93, Q42, Q54

Keywords: Aviation; Biofuels; Climate Change; Emissions Abatement

a Joint Program on the Science and Policy of Global Change, Massachusetts Institute of Technology, Cambridge, Massachusetts, U.S.A.

${ }^{\mathrm{b}}$ Laboratory for Aviation and the Environment, Department of Aeronautics and Astronautics, Massachusetts Institute of Technology, Cambridge, Massachusetts, U.S.A.

* Corresponding author: Massachusetts Institute of Technology, 77 Massachusetts Avenue, E19-411H, Cambridge, MA 02139; email: niven@mit.edu, Phone: 617-253-6958, Fax: 617-253-9845. 


\section{Introduction}

Recent estimates indicate that aviation currently accounts for approximately 5\% of total anthropogenic radiative forcing (Lee et al., 2009; Dessens et al., 2014). Furthermore, the International Civil Aviation Organization (ICAO, 2013) predicts that in the absence of mitigation measures, driven by a seven-fold increase in air traffic, total greenhouse gas (GHG) emissions associated with aviation will be 400-600\% higher in 2050 than in 2010.

To address these concerns, in 2009 the International Air Transport Association (IATA) announced that it aimed to achieve carbon-neutral growth in global airline operations from 2020 onward, and to reduce aviation GHG emissions in 2050 by $50 \%$ relative to 2005 (IATA, 2009). The industry's strategy for meeting these goals rests upon improvements in operations, airport and air traffic management, airframe and engine technologies, as well as on large-scale introduction of aviation biofuels that have significantly lower GHG emissions on a lifecycle basis than petroleumderived jet fuel (IATA, 2009). Hileman et al. (2014) quantify the reduction in life cycle GHG emissions intensity required to achieve the 2050 IATA goal in the U.S. They find that, after accounting for predicted growth in airline operations and fuel-efficiency improvements, aviation GHG intensity would need to decrease from $1.37 \mathrm{~g}$ of carbon dioxide equivalent $\left(\mathrm{CO}_{2} \mathrm{e}\right)$ per kilogram-kilometer in 2005 to $0.22 \mathrm{~g}$ in 2050 ; a decrease of $84 \%$.

Motivated by energy security and climate concerns, the U.S. Federal Aviation Administration (FAA) has established a voluntary goal that one billion gallons ( 3.8 billion liters) of alternative jet fuel is consumed annually from 2018 onward in the U.S. (FAA, 2011). This goal includes renewable fuel targets set by the U.S. Air Force and Navy, so the biofuel goal for commercial aviation is a fraction of this amount.

Operating concurrently with the FAA's biofuel goal, the National Renewable Fuel Standard (RFS2) regulates biofuels used in ground transportation in the U.S. RFS2 sets mandates for biomass-based diesel, cellulosic biofuel, undifferentiated advanced biofuels and the total quantity of biofuels. The U.S. Environmental Protection Agency ensures that the RFS2 mandates are met by issuing a renewable identification number (RIN) for each gallon of biofuel produced and requiring refineries to purchase a certain amount of RINs for each gallon of fuel sold for ground transportation (U.S. GAO, 2014). Separate RINs and turn-in targets are issued for each biofuel category. Aviation biofuels qualify for RINs, which have a monetary value, and therefore reduce the cost of renewable jet fuel to airlines. 
Almost all biofuel currently produced is ethanol or biodiesel and, due to contamination and safety concerns, cannot be used in aircrafts (Waterland et al., 2003; Hileman et al., 2009). As these fuels account for the majority of current biofuel production, new biofuel technologies will need to be developed to that are compatibility with existing infrastructure and aircraft (Hileman et al. 2009).

Large-scale deployment of aviation biofuels from pathways suited for aviation face significant challenges. These include high production costs and lack of integration of aviation biofuels into regulatory frameworks (Carter et al., 2011, Carriquiry et al., 2011; Gegg et al. 2014), limits in scale-up due to feedstock availability (U.S. DOE, 2011, Seber et al., 2014), environmental and socio-economic consequences of large-scale land-use change and competition with food and feed needs (Searchinger et al. 2008; Kretschmer et al., 2009; Serra and Zilbermann, 2013), water consumption associated with biomass cultivation (Scown et al., 2011, Staples et al., 2013), and the time required for scaling-up biomass cultivation and conversion facilities (Richard, 2010).

This paper deals with the impact of large-scale deployment of advanced aviation biofuels from perennial grasses such as switchgrass or miscanthus using a set of technologies known as advanced fermentation. Our modeling approach relies on an economy-wide model of economic activity and energy systems to quantify the additional cost of advanced renewable jet fuel relative to its conventional counterpart, and the impact of achieving the FAA's goal on aviation operations and emissions.

We focus on biofuels from AF technologies since they are commonly regarded as one class of next-generation biofuels that face smaller environmental and economic challenges compared to traditional biofuels from oily crops or grains (Tilman et al., 2009). AF technologies can convert (non-edible) lignocellulosic biomasss from agricultural residues or perennial grasses. Energy grasses have high water, light and nitrogen use efficiency (Somerville et al., 2010), are suited for a broad range of climatic and soil conditions and can be grown on land not suitable for food crops (McLaughlin et al., 2002). This potentially reduces competition for scarce land with food or feed purposes compared to growing oily crops or grains for fuel production. Moreover, due to relatively high conversion efficiencies and low fossil fuel input requirements during processing, lifecycle GHG emissions can be significantly lower than emissions for other biofuels such as those from oily crops or grains (Staples et al., 2014). This increases the potential for emissions for emissions reduction from using aviation biofuels. Additionally, biofuels from lignocellulosic biomass that 
have associated lifecycle GHG emissions of at least $60 \%$ below those of their conventional counterpart qualify for the (currently) most stringent RFS2 biofuel sub-mandate and can therefore yield higher RIN prices, which makes production of these fuels, ceteris paribus, more viable from a business perspective compared to other biofuels.

While there is a wide body of literature that deals with $\mathrm{CO}_{2}$ abatement in the airline industry through market-based measures (e.g. Hofer et al., 2010; Malina et al., 2012, Winchester et al., 2013b), only a small amount of archival studies, as discussed below, have been published that quantify the environmental and economic impact of large-scale aviation biofuel adoption. Moreover none of the existing papers on aviation biofuels examine the impact of advanced biofuels on aviation emissions and economic activity. In addition, no study to date has incorporated the interactions between an aviation-specific renewable fuel goal fulfilled with advanced biofuels and the corresponding biofuel RIN markets under RFS2 system for transportation fuels. Finally, most existing studies either do not address production costs of aviation biofuels, or simply assume that they will converge to the price of petroleum-derived jet fuel at some assumed point in time (e.g., Sgouridis et al., 2011).

Hileman et al. (2014) assess a portfolio of mitigation options in terms of their potential contribution to meeting the air transport industry's goal of a 50\% reduction in absolute GHG emissions by 2050 relative to 2005 levels. Their results indicate that in order to achieve the industry goal, a relatively rapid adoption of new, more efficient aircraft designs would be necessary as well as the large-scale introduction of alternative fuels with low lifecycle GHG emissions compared to conventional jet fuel. In particular, in order to meet the IATA goal, they find that under the assumption that the aircraft fleet in 2050 is $116 \%$ more efficient in terms of fuel burn per kilogramkilometer compared to current-generation narrow body aircraft, $30 \%$ of jet fuel consumed would have to come from renewable sources at a lifecycle GHG footprint of $10 \%$ of that of conventional jet fuel per unit of energy consumed.

Sgouridis et al. (2011) also assess strategies for mitigating $\mathrm{CO}_{2}$ emissions from air transportation. They find that if aviation biofuels can be offered at price parity to conventional jet fuel, between $15.5 \%$ and $30.5 \%$ of total jet fuel consumption in 2024 could be from renewable fuels, which would decrease cumulative $\mathrm{CO}_{2}$ emissions from aviation between 2004 and 2024 by $5.5 \%$ to $9.5 \%$ relative to their reference case. 
Krammer et al. (2013) use a systems model for the aviation industry to simulate aviation biofuel adoption under different socio-economic and policy assumptions. Like Sgouridis et al. (2011), they assume that biofuel usage does not incur a price premium compared to conventional jet fuel, and that market uptake is only limited by fuel availability. Under these assumptions they find that $50 \%$ of global jet fuel burn could be satisfied by biofuels by 2041, and that global GHG emissions attributable to aviation would be $48-53 \%$ lower than in a baseline (no-biofuels) case.

Using a numerical general equilibrium approach, Winchester et al. (2013a) quantify the economy-wide and aviation-specific impact of using one specific class of aviation biofuels derived from oily crops. To our knowledge, this is the only study that models price differences between aviation biofuels and conventional jet fuel and the associated market impacts. Winchester et al. (2013a) find that if the FAA alternative fuels goal described above were to be met with these fuels exclusively, an implicit subsidy would have to be paid ranging from \$0.35 to \$2.69 per gallon of renewable jet fuel. The lower estimate assumes that all feedstock demand can be satisfied through rotation crops grown on fallow land that do not directly compete with food or feed crops, while the higher estimate assumes soybeans are used as the feedstock. Abatement costs are calculated at approximately $\$ 400$ per tonne of $\mathrm{CO}_{2} \mathrm{e}$ abated in the soybean case, and approximately $\$ 50$ per tonne for optimistic assumptions on the availability of oilseed rotation crops. Total GHG emissions' abatement due to the use of biofuels is calculated at approximately $1 \%$ compared to the baseline case in the year 2020 .

The remainder of this paper proceeds as follows: In section 2 we outline aviation biofuel pathways, focusing on the technology sets and feedstock considered in this paper. Section 3 presents a stylized analysis of the interaction between aviation biofuel goals and the RFS2 mandate in a simplified setting. Our modeling framework and scenarios are explained in Section 4. We present results and discuss them in Section 5. The final section concludes.

\section{Advanced fermentation biofuels}

Jet fuels are certified for use in commercial aviation through ASTM, a global standard setting organization. The first two biofuels to be certified in 2009 and 2011, respectively, were synthetic paraffinic kerosene (SPK) from biomass using a Fischer-Tropsch process, and SPK consisting of Hydroprocessed Esters and Fatty Acids (HEFA) jet fuel, also known as Hydrotreated Renewable Jet fuel (ASTM, 2011). This certification allows these fuels may be used in existing aircraft 
engines and fuel infrastructure up to a blending percentage by volume of 50\% (ASTM, 2011). While these fuels have not been deployed at large scale, some airlines are using blends on selected routes. For example, in summer 2013, United Airlines executed a purchasing agreement with Alt Air Fuels for 15 million gallons of HEFA jet fuel from animal fats and non-edible oils to use on routes from Los Angeles International Airport (United Airlines, 2013). In South Africa, Sasol is providing SPK jet fuel using a Fischer-Tropsch technology and coal as a feedstock to airlines operating at O.R. Tambo International Airport in Johannesburg (Sasol, 2011).

In June 2014, ASTM revised its aviation fuel standard to include a third type of biofuel called "Synthesized Iso-Paraffinic" (SIP) fuel, produced from hydroprocessed fermented sugars, which may be blended at a maximum of $10 \%$ by volume with conventional jet fuel (ASTM, 2014). This fuel belongs to a class of biofuels using novel technologies that involve the microorganic metabolism (fermentation) of biomass-derived sugars. In this process, polymer sugars are typically extracted from biomass and decomposed to monomer sugars using mechanical, chemical or biological means. The monomer sugars are then metabolized by a microorganism to produce energy carrying platform molecules, which are then chemically upgraded to drop-in or blendstock fuels. This class of production technologies is referred to as fermentation and advanced fermentation (AF). A number of private companies are in different stages of commercialization of technologies that can be categorized as AF, such as Amyris, LS9, Solazyme, Byogy Renewables, and Gevo. While the revised ASTM Standard currently only certifies AF jet fuel produced as SIP jet fuel (currently only produced by one company, Amyris), efforts are under way to also certify AF fuels using other technology sets, possibly at higher blending percentages (ASTM, 2013).

In this paper, we consider a technology set representative of a broad range of $\mathrm{AF}$ technologies that can produce jet fuel from perennial grasses. We chose switchgrass (Panicum virgatum) as perennial grass feedstock since its agro-economic properties are relatively well studied compared to other perennial grasses. In our analysis, conversion efficiencies, product slates (the mix of products produced), and material requirements for growing switchgrass and converting it into AF jet fuel following a recent analysis by Staples et al. (2014).

By focusing on AF jet fuel production pathways, our analysis encompasses a wide-range set of feedstock-to-fuel technologies. As well as fermentation to different platform molecules, each with unique utility requirements for upgrading to jet fuel, AF process variability may be due to the feedstock pretreatment technology employed, the overall efficiency of feedstock-to-fuel 
conversion, and/or the proportion of jet fuel in the final product slate. Additionally, significant uncertainties remain about the properties of AF processes as they are yet to be implemented at commercial scale. Building on results from Staples et al. (2014), we consider a range of capital costs, energy conversion efficiencies and product slate cases to capture uncertainties associated with fuel production costs using a nascent technology such as AF. As discussed in Section 4, estimated AF costs to produce a product slate that includes a gallon of jet fuel range from $\$ 4.32$ to $\$ 25.76$. In some cases, $100 \%$ of finished fuels are jet fuel while $\sim 40 \%$ of finished fuels are non-jet products such as diesel in other instances.

\section{A stylized analysis of aviation biofuel goals and of RFS2 mandates}

As the effect of the aviation renewable fuel goal will depend on interactions between this goal and RFS2 mandates, this section delineates these interactions in a stylized setting. Under RFS2, the RIN value for each fuel category will evolve so as to offset the higher production cost of renewable fuel compared to conventional fuel.

Although renewable jet fuel consumption is not mandated under RFS2, this fuel is eligible for RINs. AF jet fuel could qualify under the cellulosic, undifferentiated advanced and biomassesbased diesel categories. However, as the costs of AF jet fuel is likely to be higher than costs for fuels that can be used for ground transportation, renewable jet fuel will not be produced without incentives additional to those under RFS2. As there are no current plans to mandate the use of aviation biofuels, following Winchester et al. (2013a), we assume that the FAA's biofuel goal is met by airlines voluntarily purchasing a set quantity of renewable fuel each year, even though this fuel is more expensive than conventional jet fuel. From an economic perspective, an equivalent representation of this mechanism is a tax on purchases of conventional jet fuel and a subsidy to renewable jet fuel production, where the per-gallon subsidy is chosen to induce the desired level of production and the per-gallon tax is chosen so that total tax revenue is equal to the total cost of the subsidy. For these reasons, we refer to the additional costs that airlines pay to purchase renewable fuel relative to conventional fuel as an implicit subsidy.

To demonstrate how the RFS2 mandate for cellulosic fuel and the aviation biofuels goal

interact to determine the implicit subsidy to renewable jet fuel, consider a 'regular' cellulosic technology that produces fuel that cannot be used to replace jet fuel, and an advanced fermentation 
pathway that produces renewable diesel and jet fuel. ${ }^{1}$ Let $c_{R}$ denote the production for the regular cellulosic technology, and $c_{A}$ represent the production costs for advanced fermentation fuel, both in jet fuel-equivalent gallons. Additionally, reflecting current costs, assume that the regular cellulosic pathway is less expensive than the AF technology and that both biofuels are more costly than petroleum-based fuel; that is, $p<c_{R}<c_{A}$, where $p$ is the price per jet-equivalent gallon of petroleum-based fuel. Without specific incentives for renewable jet fuel, the RFS cellulosic mandate will be met using regular cellulosic fuels and, in perfectly competitive markets, the RIN price per jet-equivalent gallon $(r)$ will evolve so that $c_{R}=p+r$. Within this setting, we consider three alternative policy cases, which are summarized in Table 1.

\section{- Insert Table 1 here -}

Our first case, referred to as "Include", represents the current policy setting where renewable jet fuel is included within the RFS2 mandates and the aviation industry is not required to surrender RINs. Let $s^{\text {Include }}$ denote the implicit subsidy per gallon of renewable jet fuel in this case. If $\alpha$ gallons of renewable jet fuel are produced per gallon of total distillate $(0<\alpha \leq 1)$, for each gallon of (total) fuel produced, AF producers will receive $\alpha\left(p+r+s^{\text {Include }}\right)$ from jet fuel sales and $(1-\alpha)(p+r)$ from diesel sales. Solving for the value of $s^{\text {Include }}$ that equates AF revenue and costs results in:

$$
S^{\text {Include }}=\frac{1}{\alpha}\left\{\left(c_{A}-p\right)-r\right\}=\frac{1}{\alpha}\left\{\left(c_{A}-p\right)-\left(c_{R}-p\right)\right\}=\frac{\left(c_{A}-c_{R}\right)}{\alpha}
$$

Equation (1) illustrates that the implicit jet subsidy is independent of renewable jet production costs relative to the price of conventional fuel. That is, the RFS2 policy insulates airlines from high cellulosic fuel costs. If a pathway only produces jet fuel $(\alpha=1)$, the subsidy is equal to the difference between the cost of AF jet fuel relative to regular cellulosic fuel. If renewable jet fuel is produced jointly with renewable diesel $(\alpha<1)$, the subsidy is larger as it is only offered on a fraction of output and must compensate for losses on all gallons produced.

\footnotetext{
${ }^{1}$ Even though AF fuel qualifies for cellulosic, undifferentiated advanced, and biomass-based diesel RINs, we focus on interactions between the RFS2 mandate for cellulosic fuels and the aviation biofuel goal, as the cellulosic RIN price is currently higher than other RIN values.
} 
The relationship between the implicit jet subsidy and cellulosic-AF cost premiums for alternative values of $\alpha$ is shown in Figure 1. As illustrated by this figure and equation (1), the implicit jet subsidy will be larger: (i) the smaller the proportion of jet fuel in total distillate $(\alpha)$, and (ii) the larger the difference between the cost of AF and regular cellulosic fuel.

\section{- Insert Figure 1 here -}

We further illuminate two outcomes that may arise under changes to the RFS2 policy. The first variation we consider, referred to as "Additional", is an aviation renewable jet fuel goal specified as an additional mandate for aviation fuels within RFS2. In this case, RINs associated with jet fuel production can not be sold to ground transportation fuel providers and the implicit subsidy required to induce $\mathrm{AF}$ production would be:

$$
S^{\text {Additional }}=\left(c_{A}-p\right)+\frac{(1-\alpha)}{\alpha}\left(c_{A}-c_{R}\right)>s^{\text {Include }} \forall \alpha, 0<\alpha \leq 1
$$

If the pathway only produces jet fuel, the subsidy must compensate for the difference between production costs and the price of conventional fuel. If less than $100 \%$ jet fuel is produced, the subsidy must compensate for the AF-regular cellulosic cost difference plus the per-gallon loss (net of RIN income) on renewable diesel production multiplied by the number of diesel gallons produced per gallon of jet, which is given by $(1-\alpha) / \alpha$.

The second alternative we consider, referred to as "Exceed", is an increase in the aviation biofuel goal relative to RFS2 mandates. This change is consistent with an increase in the renewable jet goal or a decrease in RFS2 mandates, as has occurred under the EPA's visa waiver credits for cellulosic fuels in recent years. Our analysis above assumed that the cellulosic RIN value is constant. If there is a large increase in the renewable jet goal relative to RFS2 mandates, inducing renewable jet fuel production may result in renewable diesel production exceeding the combined value of mandates for which this fuel is eligible. This would drive the RIN price to zero and the implicit jet subsidy would be:

$$
s^{\text {Exceed }}=\frac{\left(c_{A}-p\right)}{\alpha}>s^{\text {Additional }} \forall \alpha, 0<\alpha<1
$$


In this case, as the implicit jet subsidy only applies to $\alpha$ units of fuel and the RIN price is zero, $s^{\text {Exceed }}$ is larger than the difference between unit production costs and the price of petroleumbased fuel.

To summarize and further compare the three policy cases, implicit jet subsidies for alternative values of $\alpha$ when $p=\$ 3, c_{R}=\$ 4$ and $c_{A}=\$ 6$ are shown in Figure 2. If RINs associated with renewable jet fuel can be sold to providers of ground transport fuel, as currently legislated and represented by the Include case, the implicit jet subsidy will depend on the cost premium between AF production and regular cellulosic fuels. If the aviation goal is specified as an additional RFS2 mandate, as in the Additional case, the jet fuel subsidy will be higher than the case where airlines are not required to purchase RINs. If the aviation goal relative to RFS2 mandates are such that RIN prices for cellulosic diesel are zero, as in the Exceed case, the implicit jet subsidy will have to compensate for the difference between AF costs and the price of conventional fuel. In all cases, the implicit subsidy to renewable jet fuel is negatively related to the proportion of advanced fermentation output that is jet fuel.

\section{- Insert Figure 2 here -}

\section{Modeling framework}

To capture interactions among the aviation and agricultural industries and the broader economy, we develop and apply a bespoke version of the Emissions Prediction and Policy Analysis for Aviation (EPPA-A) model (Gillespie, 2011). The EPPA-A model is a global recursive dynamic numerical general equilibrium model of economic activity and energy production and is built on version five the MIT EPPA model (Paltsev et al., 2005). ${ }^{2}$ The model's aggregation in outlined in Table 2. Large economies such the U.S., China and Russia are identified as separate regions and most small economies are included in composite regions. The model's sectoral aggregation includes a detailed representation of energy production and transportation. Transportation options represented in the EPPA-A model include air transport, other industrial transportation (road, rail and sea transportation) and household transportation, which is a composite of privately-owned vehicles and industrial (air and other) transportation. Energy sectors in the model include

\footnotetext{
${ }^{2}$ A public release version of the EPPA model is available at http://globalchange.mit.edu/research/IGSM/eppadl.
} 
production of primary energy (coal, crude and natural gas) and secondary energy (aviation fuel, other refined oil and electricity). Primary energy can be produced from conventional resources and non-conventional sources, such as biomass (which is discussed in detail below), oil sands and shale gas. Additionally, several electricity technologies are represented, including traditional fossil, natural gas combined cycle, and large-scale wind and solar generation.

\section{- Insert Table 2 here -}

Production of each commodity assembles primary factors and intermediate inputs using constant elasticity of substitution (CES) functions under the assumptions of perfect competition. International trade for all commodities except crude oil is modeled following the approach outlined by Armington (1969), which assumes that goods are differentiated by region of origin. Crude oils is considered to be a homogenous commodity and sells for the same price in all regions (net of transport costs). Final demand is captured by, in each region, a representative consumer that earns income from factor rewards and tax payments and allocates expenditure across goods and investment to maximize utility. The model is calibrated using economic data from the Global Trade Analysis Project database (Narayanan and Walmsley, 2008) and energy data from the International Energy Agency. The base year for the model is 2004 and it is solved through time for 2005 and in five-year increments thereafter.

We tailor the EPPA-A model to suit our needs by: (i) including conversion technologies and feedstock supplies for advanced fermentation and other biofuels, (ii) including a mechanism to enforce the goal for renewable jet fuel, and explicitly representing RFS2 biofuel mandates and RIN markets.

\section{Advanced fermentation fuel in the EPPA-A model}

We include an AF pathway in the EPPA-A model by adding production functions for switchgrass and conversion of this feedstock to liquid fuel. The nested CES-structure for switchgrass production is outlined in Figure 3, where $\sigma$ is used to indicate the elasticity of substitution between inputs in each nest. The production specification permits substitution between land and energymaterials, and between land-energy-materials and capital-labor. This structure allows endogenous 
yield improvements to changes in land prices by using more other inputs (e.g., machinery and fertilizer) and follows that used for agricultural production in Paltsev et al. (2005). Production costs for switchgrass are based on estimates from U.S. DOE (2011) and cost input shares are sourced from Duffy (2008).

\section{- Insert Figure 3 here -}

The production structure for AF fuels is sketched in Figure 4. This technology produces jet fuel and, in some case, diesel and surplus electricity by combining switchgrass and other inputs. In the top level of the nest, switchgrass and other inputs are combined in a CES nest with $\sigma_{K L I-S}$ $=0.2$ to allow producers to extract more energy per ton of biomass than specified in the base case by using more other inputs. Due to uncertainty in the development of AF production, we consider six alternative parameterizations of the production function for this technology. Staples et al. (2014) estimate AF costs under alternative assumptions regarding the product slate, the energy efficiency of biomass conversion, and capital costs. We capture the range of these estimates by considering, for low- and high- jet fuel product slate specifications, medium-cost (medium efficiency and medium capital costs), low-cost (high efficiency and low capital costs) and highcost (low efficiency and high capital costs) cases.

\section{- Insert Figure 4 here -}

Revenue by product and costs by input per gallon of jet fuel produced for each of the six alternatives are presented in Table 3 . In these calculations, revenues and costs by commodity are mapped to sectors identified in EPPA-A. As a result, diesel output is a perfect substitute for the other refined oil sector, and inputs of chemicals and enzymes are sourced from energy-intensive industry. Revenue from the sale of RINs and the implicit subsidy to renewable jet fuel are not included in this tables, as these are derived endogenously in our modeling framework.

- Insert Table 3 here - 
In the low- and high-jet specifications, $62 \%$ and $100 \%$, respectively, of total finished fuel output is jet fuel and the remainder is diesel. Revenue per gallon of jet fuel produced is higher in the low-jet case than the high-jet specification due to diesel sales, but costs are also greater, so Table 3 reports costs divided by revenue to facilitate comparison across alternative specifications. In low-cost cases, which assume high energy conversion efficiency, AF produces surplus electricity, while this process purchases electricity in other cost cases. Reflecting assumptions underpinning these cases, feedstock and capital costs are significantly higher in low-cost cases than high-cost cases. Other factors constant, production costs are higher for high-jet cases than low-jet alternatives as high-jet specifications employ fermentation to an alcohol platform molecule, which has a greater overall feedstock-to-fuel conversion efficiency than the platform molecules in low-jet cases. The cost and revenue numbers in Table 3 are base prices and change in our simulations due to price changes and, where permitted, substitution possibilities.

Table 3 also reports lifecycle $\mathrm{CO}_{2}$ equivalent $\left(\mathrm{CO}_{2} \mathrm{e}\right)$ emissions for each cost case, measured in grams of $\mathrm{CO}_{2} \mathrm{e}\left(\mathrm{gCO}_{2} \mathrm{e}\right)$ per megajoule (MJ). Stratton et al. (2011) estimate that lifecycle $\mathrm{CO}_{2}$ emissions from conventional jet fuel are $87.5 \mathrm{gCO}_{2} \mathrm{e} / \mathrm{MJ}$. Relative to this estimate, lifecycle emissions in low-cost (high energy conversion efficiency) cases are about $15 \%$ of those for conventional fuel and the corresponding number is around $60 \%$ in medium-cost cases. In highcost cases, largely due to a relatively low energy conversion efficiency, lifecycle emissions for AF fuel are similar to those for conventional fuel.

\section{Other biofuel characteristics in the EPPA-A model}

Other biofuels added to the EPPA-A model for our analysis include pathways for corn ethanol, soybean biodiesel, cellulosic ethanol, and undifferentiated advanced biofuel. These pathways are added to the model by including, for each pathway, production functions for biofuel crops and conversion of feedstocks to biofuels. Our representation of these production functions follows Winchester et al. (2013a), except the function for switchgrass cultivation which follows that outlined in Figure 3. Guided by Humbird et al. (2011), the production costs for cellulosic ethanol are set to $\$ 2.26 /$ gal ( $\$ 3.80$ per jet-equivalent gallon).

We also augment the EPPA-A model to include RFS2 mandates and associated RIN markets for corn ethanol, biomass-based diesel, cellulosic biofuels, and undifferentiated advanced 
biofuels. These mandates and markets are modeled by including a separate permit system for each type of fuel, as detailed by Winchester et al. (2013a). AF fuel is eligible for biomass-based diesel, cellulosic and undifferentiated advanced RINs, which are allocated on an energy-equivalent basis. Similarly, we enforce the FAA's renewable fuel goal using a permit system that grants one permit for each gallon of renewable jet fuel produced and requires commercial aviation and the military to purchase, respectively, $\delta_{C}\left(0 \leq \delta_{C} \leq 1\right)$ and $\delta_{M}\left(0 \leq \delta_{M} \leq 1\right)$ permits per gallon of jet fuel consumed. The parameters $\delta_{C}$ and $\delta_{M}$ are determined endogenously in EPPA-A to meet the volumetric renewable fuel targets outlined in Section 2. This specification is equivalent to the revenue-neutral tax-subsidy system discussed Section 3, where the commercial aviation permit value equals the implicit per-gallon subsidy from airlines to producers of renewable jet fuel.

Several interactions among AF outcomes and other biofuels are captured in our modeling framework. First, the cellulosic ethanol and AF pathways compete with each other for the same feedstock. Second, mandates for other biofuels will place upward pressure on land prices. Third, if AF processes produce diesel as a co-product with jet fuel, RIN prices for cellulosic (and possibly also biomass-based diesel and undifferentiated advanced fuels) will influence the implicit subsidy to renewable jet fuel, as highlighted in Section 3.

\section{Scenarios}

We assess the economic and environmental impacts of the U.S. goal for renewable jet fuel through 2030 under an AF pathway by defining eight scenarios. The first, Reference, simulates economic activity and aviation operations without any biofuel policies and is used as a benchmark for other scenarios. In the Reference case, we calibrate the EPPA-A model to jet fuel price forecast from EIA (2013) and aviation output, measured in revenue passenger miles (RPMs), and fuel consumption forecasts from the FAA (2013). Our next scenario, RFS2, simulates renewable fuel mandates set out in the Energy and Independency and Security Act of 2009. As the Act does not set targets beyond 2022, we extent the mandates by assuming that the target for each fuel relative to total transport fuel consumption is constant from 2022 onward.

Our remaining six scenarios impose the FAA's goal that one billion gallons of renewable fuel is consumed by U.S. aviation each year from 2018 onwards, in addition to the renewable fuel targets in the RFS2 scenario. As noted in Section 1, the FAA one-billion gallon per year biofuel 
goal from 2018 includes targets for U.S. Navy and Air Force. The Navy aims at procuring 50\% of its energy consumption afloat (marine fuels and jet fuel) from alternative sources by 2020 (U.S. Navy, 2010), which would amount to approximately 280 million gallons of annual alternative fuel consumption in 2020 (U.S. GAO, 2014). The Air Force originally set a renewable jet fuel target for 2016 but has since moved its target date to 2020. Under the original target, $50 \%$ of the Air Force's total domestic aviation fuel use was to be met by fuel blends that included alternative fuels that are "greener" - presumably in terms of GHG emissions - than conventional counterparts (U.S. Air Force, 2009). Carter et al. (2011) calculate that this target equates to 370 million gallons of renewable fuel per year. Under the revised target, $50 \%$ of fuel used for non-contingency operations must be blended with alternative fuel (U.S. Air Force, 2013), but non-contingency is not specified. Due to this ambiguity, we consider an Air Force target consistent with the original specification (370 million gallons per year) starting from the revised implementation date (2020). Consequently, our analysis examines the economic and emissions impact of a commercial aviation biofuel consumption goal of 350 million gallons per year from 2020 onwards.

Reflecting uncertainties regarding the development of AF pathways, we simulate the renewable jet fuel goals for commercial aviation and military use separately for the six parameterization of this technology outlined in Table 3. All renewable jet fuel scenarios are consistent with the Include policy case considered in Section 3, as this case is consistent with current legislation.

\section{Results}

We solve the model in five-year increments from 2005 to 2030 and focus our discussion of modeling outcomes on 2030 to illuminate important findings. Results for the U.S. in this year are reported in Table 4. In the Reference scenario, which does not include any biofuel mandates or goals, corn ethanol is the only biofuel produced, due to the higher cost of other biofuels relative to conventional fuel. In 2030, U.S. commercial aviation flies 1.3 billion RPMs and consumes 25,387 million gallons of jet fuel. Using the estimates reported in Section 4, lifecycle $\mathrm{CO}_{2} \mathrm{e}$ emissions from this fuel are 295 million metric tonnes (t), which represents a $25 \%$ increase relative to the 2005 level. 


\section{- Insert Table 4 here -}

When RFS2 renewable fuel mandates are simulated, the cellulosic target is met by fuel from the cellulosic ethanol technology, as production costs for this technology are lower than those for AF under all cost assumptions. The cellulosic RIN price, in 2010 dollars, is $\$ 0.35$ per jetequivalent gallon ( $\$ 0.21$ per gallon of ethanol). There is a small decrease in the price of jet fuel relative to the Reference scenario (from $\$ 3.33$ to $\$ 3.31$ ) as RIN prices passed on to consumers of ground transportation fuel reduce demand for these fuels, which ultimately depresses the (net of RIN value) price of refined oil products. Despite the decrease in the jet fuel price, aviation operations, fuel use and emissions decrease relative to the Reference scenario due to a GDPinduced decrease in demand for aviation services.

In the six scenarios that impose the U.S. goal for renewable jet fuel, AF pathways produce enough fuel to meet the aviation goal and the balance of the RFS2 mandate for cellulosic fuel is sourced from the cellulosic ethanol technology. AF fuel in all renewable jet scenarios are allocated cellulosic RINs, as the value of these RINs is greater than value of other applicable RINs.

In the medium-cost, high-jet case, the cost of renewable jet fuel is $\$ 8.25 /$ gallon. For each gallon of jet fuel, renewable jet fuel producers receive $\$ 0.35$ for cellulosic RINs, so the price of renewable jet fuel is $\$ 7.86$ (\$8.21 minus $\$ 0.35)$. As the price of conventional jet fuel is $\$ 3.20 /$ gallon, this represents an implicit subsidy from airlines to renewable jet fuel producers of $\$ 4.65$ (\$7.86 minus \$3.21) per gallon of renewable jet fuel. The average jet fuel price reported in Table 4 is the average price paid by commercial aviation when this industry purchases 25,065 million gallons of conventional fuel at $\$ 3.21 /$ gal and 350 million gallons at a price of $\$ 7.86 /$ gal. As renewable fuel represent only $1.4 \%$ of total commercial aviation consumption, the average jet price is very close to the price of conventional fuel. Relative to the RFS2 scenario, the aviation renewable fuel goal reduces RPMs and fuel consumption by, respectively $0.80 \%$ and $0.88 \%$. The larger reduction in fuel consumption relative to RPMs reflects price-induced efficiency improvements. Combined, the substitution of conventional biofuels and reduced fuel use decrease lifecycle $\mathrm{CO}_{2} \mathrm{e}$ emissions from 25,228 million tonnes (Mt) to 25,065 Mt.

In the medium-cost, low-jet scenario, the implicit subsidy to renewable jet fuel (\$11.36/gal) is higher than in the corresponding High-jet simulation $(\$ 8.25 / \mathrm{gal})$. This is because, as highlighted 
in Section 3, the implicit jet subsidy must also compensate losses on the production of renewable diesel. This results in an average jet fuel price of $\$ 3.32 /$ gal and, relative to the high-jet case, drives slightly larger reductions in RPMs, fuel consumption and $\mathrm{CO}_{2}$ emissions. There is no change in renewable jet fuel use across scenarios, as the consumption of this fuel is set by the goal.

In low-cost cases, the implicit jet subsidy is $\$ 0.45 / \mathrm{gal}$ and $\$ 0.50 / \mathrm{gal}$ when there are, respectively, high- and low-jet product slates. These subsidies result in, relative to the RFS2 scenario, small changes in the average jet price and consequently small changes $(<0.1 \%)$ in RPMs and fuel consumption. In high-cost cases, the implicit jet subsidy is $\$ 13.12$ and $\$ 20.85 / \mathrm{gal}$ in, respectively, high- and low-jet product slate settings. Compared to other cases, there are relatively large decreases in GDP in high-cost settings, as more resources are diverted from other activities to meet the renewable jet fuel goal when capital costs are high and energy conversion efficiency is low. Relatively large increases in the average jet price and decreases in GDP reduce RPMs by, respectively, $2.3 \%$ and $3.6 \%$ for high- and low-jet cases, relative to the RFS2 scenario. The corresponding decreases in fuel consumption are $2.5 \%$ and $3.8 \%$.

\section{$\mathrm{CO}_{2}$ emissions and abatement costs}

We further investigate the impact of the renewable jet fuel goal on emissions by reporting proportional changes in lifecycle emissions - due to biofuel consumption and reduced total fuel use - relative to the RFS2 scenario in Table 5. In low-cost cases, emissions fall by $1.3 \%$ relative to the RFS2 scenario, which is mostly due to the substitution of regular fuel for biofuel. In the medium- and high-cost cases, due to lower energy conversion efficiency, emissions reductions due to biofuels are smaller than in the low-cost case, but higher fuel costs lead to larger emissions reductions due to reduced fuel use. The net effect is that emissions reduction are larger in highcost than low-cost cases. As a result, the largest reduction in emissions is for the high-cost, lowjet case (which has the highest implicit jet subsidy), even though there is a small increase $(0.02 \%)$ in emissions due to biofuel consumption owing to greater lifecycle emissions from renewable fuel than conventional fuel.

- Insert Table 5 here - 
To examine the cost effectiveness of emissions reductions, Table 5 also reports the number of gallons of conventional fuel that need to be replaced by biofuel to abatement one metric tonne of $\mathrm{CO}_{2} \mathrm{e}$, and $\mathrm{CO}_{2} \mathrm{e}$ abatement costs. These estimates include "well-to-wake" GHG emissions from fuel production, as well as $\mathrm{CO}_{2}$ emissions from combustion, but do not include non- $\mathrm{CO}_{2}$ combustion emissions such as soot or water vapor. In the low-cost, high-jet case, using the lifecycle $\mathrm{CO}_{2} \mathrm{e}$ estimates discussed in Section 4, replacing conventional fuel with biofuel reduces emission by $75.8 \mathrm{gCO}_{2} \mathrm{e}(87.5$ minus 11.7$)$ per $\mathrm{MJ}$ or fuel, which equates to 10.07 kilograms per gallon of fuel. Consequently, 99.3 gallons of biofuel are required to abate one metric ton of $\mathrm{CO}_{2} \mathrm{e}$ emissions.

Abatement costs due to the direct effect in Table 5 are calculated by multiplying the per gallon renewable jet subsidy by the number of gallons of biofuel use required to reduce emission by one metric ton. As enforcing the goal also leads to price-induced changes in fuel efficiency and demand for aviation services (indirect effects), we also report abatement costs due to direct and indirect effects. These costs are calculated by dividing the additional fuel costs paid by airlines by the decrease in emissions (relative to the RFS2 scenario). ${ }^{3}$ Indirect effects have a small impact on abatement costs in low-cost cases, where abatement costs are $\$ 42.0 / \mathrm{tCO}_{2} \mathrm{e}$ and $\$ 46.9 / \mathrm{tCO}_{2} \mathrm{e}$ in, respectively, high- and low-jet settings. In contrast, due to higher average jet fuel prices and larger income-induced changes in demand, indirect effects significantly reduce abatement costs in other cases, but abatement costs are also higher. In the medium-cost case, abatement costs are between $\$ 318 / \mathrm{tCO}_{2} \mathrm{e}$ and $\$ 410 / \mathrm{tCO}_{2} \mathrm{e}$, and the corresponding numbers in the high-cost case are $\$ 609 / \mathrm{tCO}_{2} \mathrm{e}$ and $\$ 650 / \mathrm{tCO}_{2} \mathrm{e}$.

\section{Conclusions}

This paper considered the economic and emissions impacts on U.S. commercial aviation of the FAA's renewable jet fuel goal when this target is met using AF fuel. As this fuel is more expensive than conventional fuel, we assumed that the goal was met by commercial aviation voluntarily purchasing renewable fuel at a price premium, which is equivalent to airlines offering biofuel producers an implicit subsidy.

\footnotetext{
${ }^{3}$ As some of the additional cost of renewable jet fuel relative to convention fuel is absorbed by ground transportation providers through the purchase of cellulosic RINs, the economy-wide abatement cost is higher than the total abatement cost reported in Table 5.
} 
In a simplified setting, we showed that RINs offered under RFS2 reduced the implicit subsidy required to induce production of AF jet fuel. This analysis also demonstrated, that as the jet fuel subsidy has to cover losses on all fuel produced, the implicit subsidy was higher when only a fraction AF output was jet fuel than when $100 \%$ of distillate was jet fuel. In this setting, we also investigated how two possible policy changes may influence the subsidy to renewable jet fuel. First, specifying the goal for renewable jet fuel as a requirement additional to the mandates in RFS2 would increase the implicit subsidy. Second, under certain policy changes, the production of diesel as a co-product with renewable jet fuel may drive RFS2 RIN prices to zero. In this case, a higher implicit subsidy to renewable jet fuel is required than in our core policy case.

The paper quantified the impact of AF fuels using an economy-wide model that included detailed engineering estimates of AF technologies. Due to uncertainty surrounding the evolution of AF technologies, we considered a range of assumptions concerning capital costs, energy conversion efficiency and the product slate. The most favorable case assumed high energy conversion efficiency and low capital costs. Under these assumptions in 2030, the implicit subsidy to renewable jet fuel was $\$ 0.45$ when all distillate was jet fuel and $\$ 0.50$ when only $60 \%$ of distillate was jet fuel. In a medium-cost case, the corresponding subsidies were $\$ 4.69$ and $\$ 7.73$, and in a high-cost case the numbers were $\$ 13.12$ and $\$ 20.85$. Despite the large variation in subsidies across cases, the impact of the goal on the average jet fuel price was moderated by the small proportion of renewable fuel $(\sim 1.4 \%)$ in total fuel purchased by airlines. Consequently, there were small changes in aviation operations in all scenarios. Decreases in emissions from commercial aviation in 2030, relative to case without renewable jet fuel, ranged from $1.3 \%$ to $3.8 \%$, and 2030 emissions were more than $20 \%$ higher than 2005 emissions in all cases. Costs per metric ton of $\mathrm{CO}_{2} \mathrm{e}$ abated ranged from $\$ 42$ to $\$ 652$. Interestingly, in high-cost cases, the high cost of abating emissions by replacing conventional fuel with renewable jet fuel had a positive feedback that reduced emissions by decreasing aviation operations (through higher airfares) and inducing improvements in fuel efficiency, which ultimately reduced abatement costs. Furthermore, due to low conversion efficiency and ultimately high biofuel lifecycle emissions, reduced fuel use accounted for $96 \%$ of total emissions reductions in the high-cost, high-jet case.

We note that the calculated abatement costs for AF jet fuel of approximately $\$ 300$ to $\$ 400$ per $\mathrm{tCO}_{2} \mathrm{e}$ in the year 2030 for the medium fuel costs assumptions are similar to the abatement costs for jet fuel from soybean oil using the HEFA process of around $\$ 400$ per $\mathrm{tCO}_{2} \mathrm{e}$ as quantified 
by Winchester et al. (2013a). However, relative to HEFA fuels, there are additional opportunities for reductions in abatement costs for AF jet fuels. These include engineering a product slate that solely consists of jet fuel, which reduces the overall fuel volume to be produced and correspondingly reduces the implicit subsidy that is needed to achieve the FAA goal. There are also additional prospects for efficiency improvements of the novel technology during commercialization. Combined, these developments could reduce abatement costs - as shown in our low-cost, high jet product slate simulation - to approximately $\$ 40$ per $\mathrm{tCO}_{2} \mathrm{e}$, which is within the range of projected carbon prices for the year 2030 under a cap-and-trade regime proposed by the U.S. government in 2009 (Winchester et al., 2013b). Other abatement options for the airline industry currently (July 2014) cost around $\$ 8$ per $\mathrm{tCO}_{2} \mathrm{e}$ in case of emission allowances under the EU ETS and around $\$ 0.20$ per $\mathrm{tCO}_{2} \mathrm{e}$ for carbon offsets in the form of certified emission reductions - but have historically been as high as $\$ 40$ and $\$ 20$ per $\mathrm{tCO}_{2} \mathrm{e}$ for emission allowances and offsets, respectively (European Energy Exchange, 2014; Quandl, 2014). These numbers suggest that the emissions offsetting scheme proposed by IATA is currently more cost-effective than using biofuels to abate aviation emissions, but biofuels may play a future role as the cost of these technologies decrease and global demand for emissions reduction credits increase the price of offsets. 


\section{Acknowledgements}

The authors wish to thank James I. Hileman and Hakan Olcay for helpful comments and suggestions. Remaining errors are our responsibility. This work is funded by the U.S. Federal Aviation Administration (FAA) and Defense Logistics Agency Energy (DLA Energy) through Project 47 of the Partnership for Air Transportation Noise and Emissions Reduction (PARTNER). The Joint Program on the Science and Policy of Global Change is funded by the U.S. Department of Energy and a consortium of government and industrial sponsors (for the complete list see http://globalchange.mit.edu/sponsors/all). Any opinions, findings, and conclusions or recommendations expressed in this material are those of the authors and do not necessarily reflect the views of the FAA or DLA Energy. 


\section{References}

Armington, P.S., 1969. A theory of demand for products distinguished by place of production. IMF Staff Papers, 16: 159-76.

ASTM, 2011. Standard Specification for Aviation Turbine Fuel Containing Synthesized Hydrocarbons, Designation D7566-12a. ASTM International, West Conshohocken, PA.

ASTM, 2013. New Specification for Research Report: Evaluation of Alcohol to Jet Synthetic Paraffinic Kerosenes (ATJ-SPKs), Work Item WK41378, ASTM International, West Conshohocken, PA.

ASTM, 2014. Standard Specification for Aviation Turbine Fuel Containing Synthesized Hydrocarbons, Designation D7566-14a. ASTM International, West Conshohocken, PA.

Carriquiry, M. A., Du, X., Timilsina, G. R., 2011. Second generation biofuels: Economics and policies. Energy Policy, 39: 4222-4234.

Carter, N., Stratton, R., Bredehoeft, M., Hileman, J., 2011. Energy and environmental viability of select alternative jet fuel pathways. In: 47th AIAA Joint Propulsion Conference, San Diego, CA.

Dessens, O., Köhler, M. O., Rogers, H. L., Jones, R. L. Pyle, J. A., 2014. Aviation and climate change. Transport Policy, in press.

Duffy, M, 2008. Estimated costs for production, storage and transportation of switchgrass, $A g$ Decision Maker, File A1-22, Department of Economics University Extension, Iowa State University. Available at: https://www.extension.iastate.edu/agdm/crops/html/a1-22.html.

Energy Information Administration, 2013. Annual energy outlook with projections to 2040. Energy Information Administration: Washington, DC. Available at: http://www.eia.gov/forecasts/aeo/ [Accessed November 13, 2013].

European Energy Exchange, 2014. EU Emission Allowances, Secondary Market, Market data from July $2^{\text {nd }}$ 2014. Available at: http:Iwww.eex.com [Accessed July 3, 2014].

FAA (Federal Aviation Administration), 2013. FAA aerospace forecasts FY 2013-2033. Federal Aviation Administration: Washington, DC. Available at: http://www.faa.gov/about/office_org/headquarters_offices/apl/aviation_forecasts/aerospa ce_forecasts/2013-2033/. [Accessed November 13, 2013].

FAA (Federal Aviation Administration), 2011. Destination, 2025, Available at: http:// www.faa.gov/about/plans_reports/media/destination2025.pdf. [Accessed April 24, 2014]. 
FAA (Federal Aviation Administration), 2013. FAA aerospace forecasts FY 2013-2033. Federal Aviation Administration: Washington, DC. Available at: http://www.faa.gov/about/office_org/ headquarters_offices/apl/aviation_forecasts/aerospace_forecasts/2013-2033/ [Accessed November 13, 2013].

Gegg, P., Budd, L., Ison, S., 2014. The market development of aviation biofuel: Drivers and constraints. Journal of Air Transport Management, 39: 34-40.

Gillespie, C.W., 2011. A general equilibrium analysis of climate policy for aviation. Masters Thesis, Massachusetts Institute of Technology, Cambridge, MA.

Hileman J. I, Ortiz D. S, Bartis J. T., Wong, H. S., Donohoo, P. E., Weiss, M. A., Waitz, I. A., 2009. Final report of PARTNER Project 17, Report No. PARTNER-COE-2009-001 Cambridge, MA.

Hileman, J. I., De la Rosa Blanco, E., Bonnefoy, P. A., Carter, N. A., 2013. The carbon dioxide challenge facing aviation. Progress in Aerospace Sciences. 63: 84-95.

Hofer, C., Dresner, M.E., Windle, R.J., 2010. The environmental effects of airline carbon emissions taxation in the U.S. Journal of Transportation Research Part D: Transport and Environment, 15: 37-45.

Humbird, D, Davis, R.., Tao, L., Kinchin, C., Hsu, D., Aden, A., Schoen, P., Lukas, J., Olthof, B., Worley, M., Sexton, D., Dudgeon D., 2011. Process Design and Economics for Biochemical Conversion of Lignocellulosic Biomass to Ethanol, National Renewable Energy Laboratory, Golden, CO.

IATA (International Air Transport Association), 2009. A global approach to reducing aviation emissions. Available at: http://www.iata.org/SiteCollectionDocuments/ Documents/Global_Approach_Reducing_Emissions_251109web.pdf [Accessed April 12, 2013].

ICAO (International Civil Aviation Organization), 2013. Environmental report. Destination Green, Montreal.

Krammer, P., Dray, L., Köhler, M. O., 2013. Climate-neutrality versus carbon-neutrality for aviation biofuel policy. Transportation Research Part D: Transport and Environment, 23: 64-72.

Kretschmer, B., Narita, D., Peterson, S., 2009. The economic effects of the EU biofuel target. Energy Economics, 31: S285-S294. 
Lee, D. S., Fahey, D. W., Forster, P. M., Newton, P. J., Wit, R. C., Lim, L. L., Owen, B., Sausen, R., 2009. Aviation and global climate change in the 21st century. Atmospheric Environment, 43 (22): 3520-3537.

Malina, R., McConnachie, D., Winchester, N., Wollersheim, C., Paltsev, S., Waitz, I.A., 2012. The impact of the European Union emissions trading scheme on U.S. aviation. Journal of Air Transport Management 19: 36-41.

McLaughlin, S. B., De La Torre Ugarte, D. G., Garten, C. T., Lynd, L. R., Sanderson, M. A., Tolbert, V. R., Wolf, D. D., 2002. High-value renewable energy from prairie grasses. Environmental Science \& Technology, 36: 2122-2129.

Narayanan, B.G., Walmsley, T.L., 2008. Global Trade, Assistance, and Production: The GTAP 7 database. Center for Global Trade Analysis, Purdue University, West Lafayette, IN.

Richard T. L., 2010. Challenges in scaling up biofuels infrastructure. Science, 329:793-796.

Paltsev, S., Reilly, J., Jacoby, H.D., Eckaus, R.S., McFarland, J., Sarofim, M., Asadooria, M., Babiker, M., 2005. The MIT Emissions Prediction and Policy Analysis (EPPA) model: Version 4. Joint Program on the Science and Policy of Global Change, Report No. 125, Massachusetts Institute of Technology, Cambridge, MA.

Quandl, 2014. Available at: http://www.quandl.com/futures/ice-cer-emissions-futures [Accessed July $\left.1^{\text {st }}, 2014\right]$.

Sasol, 2011. Sasol Facts, Johannesburg, South Africa, Avaliable at http://www.sasol.com/sasol_internet/downloads/11029_Sasol_Facts_2011_13097867652 89.pdf [Accessed April 8, 2012].

Scown, C. D., Horvath, A., McKone, T. E., 2011. Water footprint of U.S. transportation fuels. Environmental science \& technology, 45(7), 2541-2553.

Searchinger, T., Heimlich, R., Houghton, R. A., Dong, F., Elobeid, A., Fabiosa, J., Tokgoz, S., Hayes, D., Yu, T. H., 2008. Use of U.S. croplands for biofuels increases greenhouse gases through emissions from land-use change. Science, 319: 1238-1240.

Seber, G., Malina, R., Pearlson, M. N., Olcay, H., Hileman, J. I., Barrett, S. R., 2014. Environmental and economic assessment of producing hydroprocessed jet and diesel fuel from waste oils and tallow. Biomass and Bioenergy, 67: 108-118.

Serra, T., Zilberman, D., 2013. Biofuel-related price transmission literature: A review. Energy Economics, 37: 141-151. 
Sgouridis, S., Bonnefoy, P., Hansman, R.J., 2011. Air transportation for a carbon constrained world: long-term dynamics of policies and strategies for mitigating the carbon footprint of commercial aviation. Transportation Research Part A: Policy and Practice, 45(10), 10771091.

Somerville, C., Youngs, H., Taylor, C., Davis, S. C., Long, S. P., 2010. Feedstocks for lignocellulosic biofuels. Science, 329: 790-792.

Staples, M. D., Olcay, H., Malina, R., Trivedi, P., Pearlson, M. N., Strzepek, K., Paltsev, S., Wollersheim, C., Barrett, S. R., 2013. Water consumption footprint and land requirements of large-scale alternative diesel and jet fuel production. Environmental science \& technology, 47: 12557-12565.

Staples, M.D., Malina, R., Olcay, H., Pearlson, M.N., Hileman, J.I., Boies, A., Barrett, S.R.H., 2014. Lifecycle greenhouse gas footprint and minimum selling price of renewable diesel and jet fuel from advanced fermentation production technologies. Energy and Environmental Science, 7, 1545-1554.

Stratton, R., Wong, H.M., Hileman, J., 2011. Quantifying variability in life cycle greenhouse gas inventories of alternative middle distillate transportation fuels. Environmental Science and Technology, 45(10): 4637-4644.

Tilman, D., Socolow, R., Foley, J. A., Hill, J., Larson, E., Lynd, L., Pacala, S., Reilly, J., Searchinger, T., Somerville, C., Williams, R., 2009. Beneficial biofuels - the food, energy, and environment trilemma. Science, 325: 270-271.

U.S. Air Force, 2009. U.S. Air Force energy plan: 2010.

U.S. Air Force, 2013. U.S. Air Force energy strategic plan: 2013.

U.S. DOE (Department of Energy). 2011. U.S. billion-ton update: Biomass supply for a bioenergy and bioproducts industry. R.D. Perlack and B.J. Stokes (Leads), ORNL/TM-2011/224. Oak Ridge National Laboratory, Oak Ridge, TN..

U.S. GAO (Government Accountability Office), 2014: Alternative Jet Fuels: Federal Activities Support Development and Usage, but Long-term Commercial Viability Hinges on Market Factors. GAO report GAO-14-407.

U.S. Navy, 2010. A Navy energy vision for the 21st century.

United Airlines, 2013. United Airlines and AltAir Fuels to Bring Commercial-Scale, CostCompetitive Biofuels to Aviation Industry, Press release, June 4 2013, Chicago, IL. 
Waterland, L.R., Venkatesh S., Unnasch, S., 2003. Safety and performance assessment of ethanol/diesel blends (e-diesel), NREL/SR-540-34817, National Renewable Energy Laboratory technical report.

Winchester, N., McConnachie, D., Wollersheim, C., Waitz, I.A, 2013a. Economic and emissions impacts of renewable fuel goals for aviation in the U.S. Transportation Research Part A: Policy and Practice, 58, 116-128.

Winchester, N., Wollersheim, C., Clewlow, R., Jost, N.C., Paltsev, S., Reilly, J., Waitz, I.A., 2013b. The impact of climate policy on U.S. aviation. Journal of Transport Economics and Policy, 47: 1-15. 


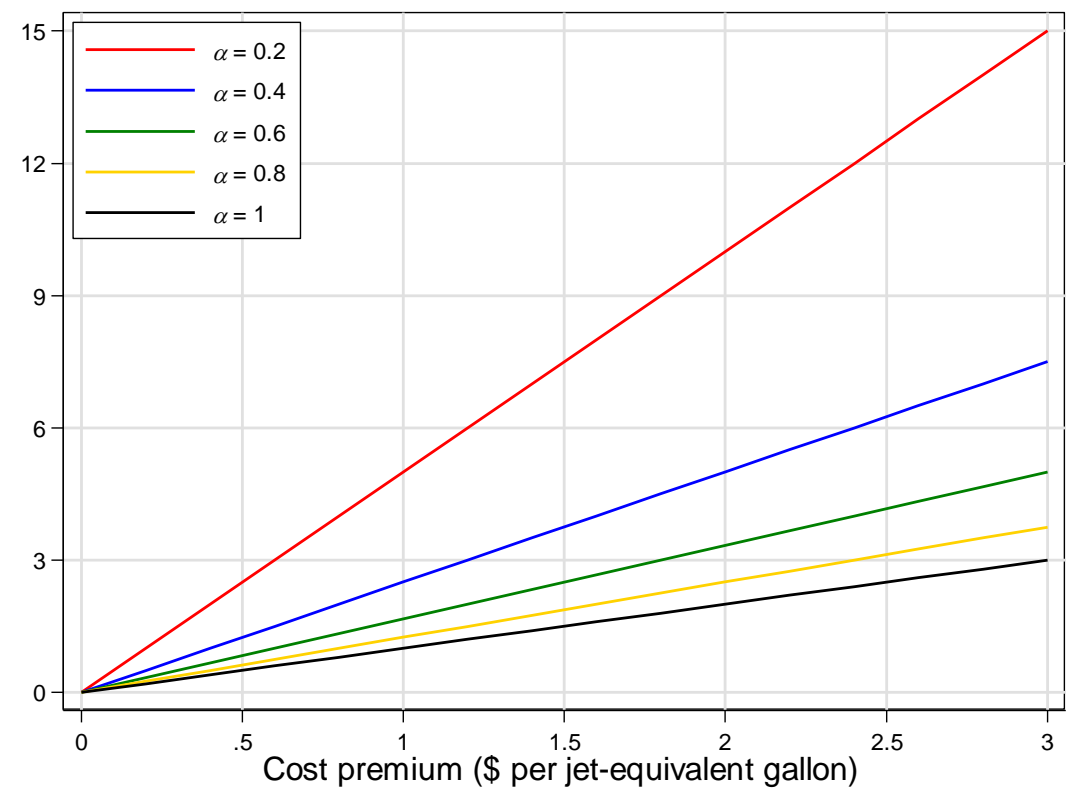

Figure 1. The relationship between the implicit jet subsidy and the cellulosic-advanced fermentation cost premium. 


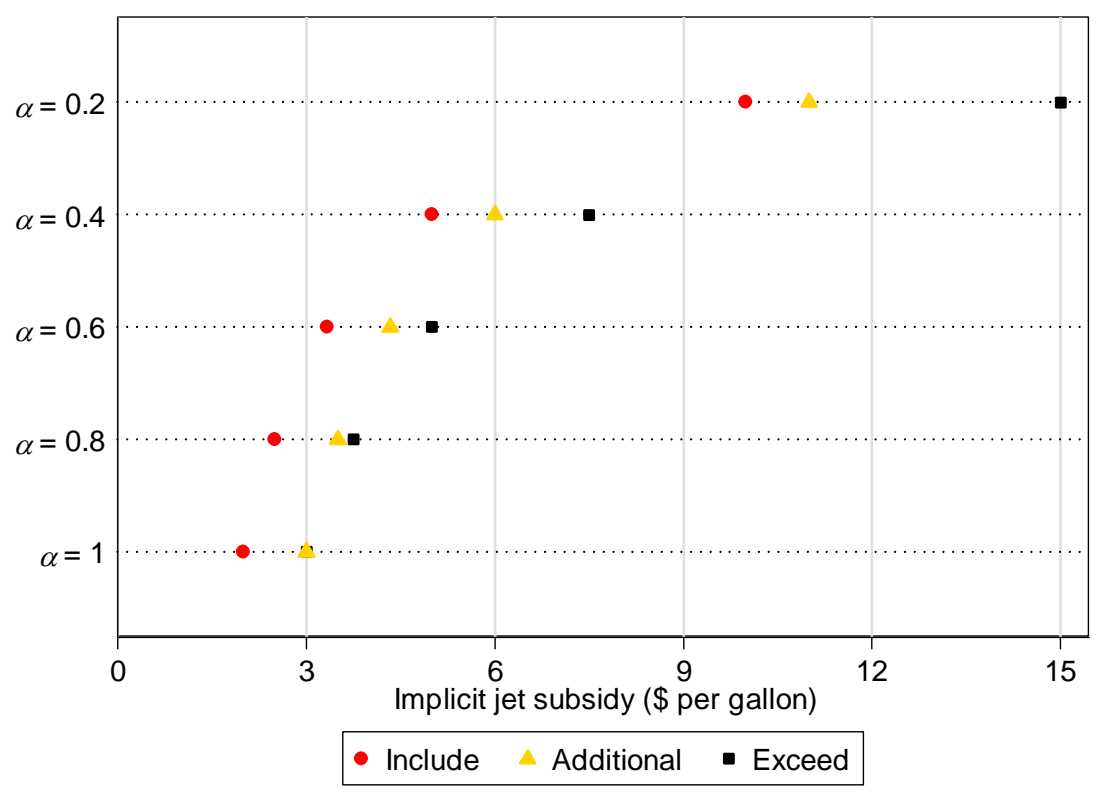

Figure 2. The implicit jet subsidy for alternative aviation biofuel goal cases ( $p=\$ 3, c_{R}=\$ 4$ and $c_{A}=\$ 6$ ). 


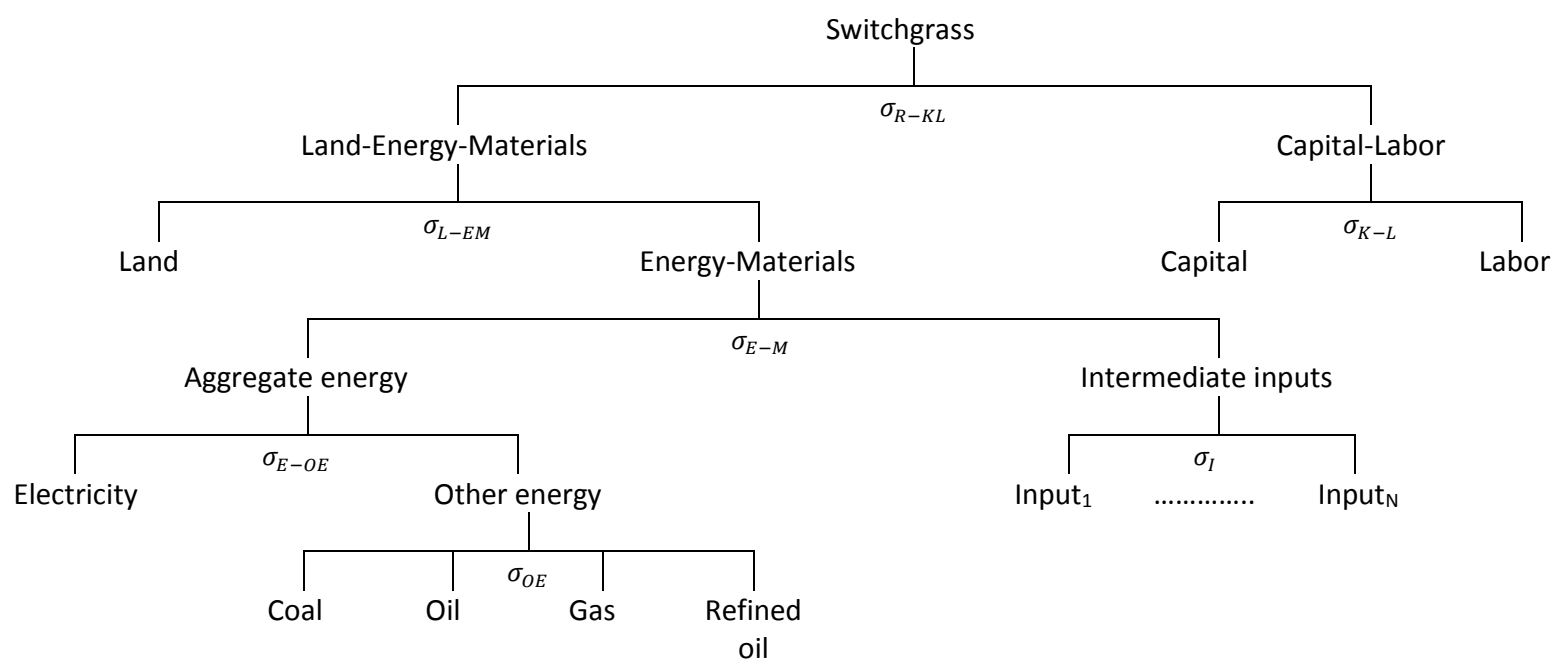

Figure 3. Switchgrass production. 


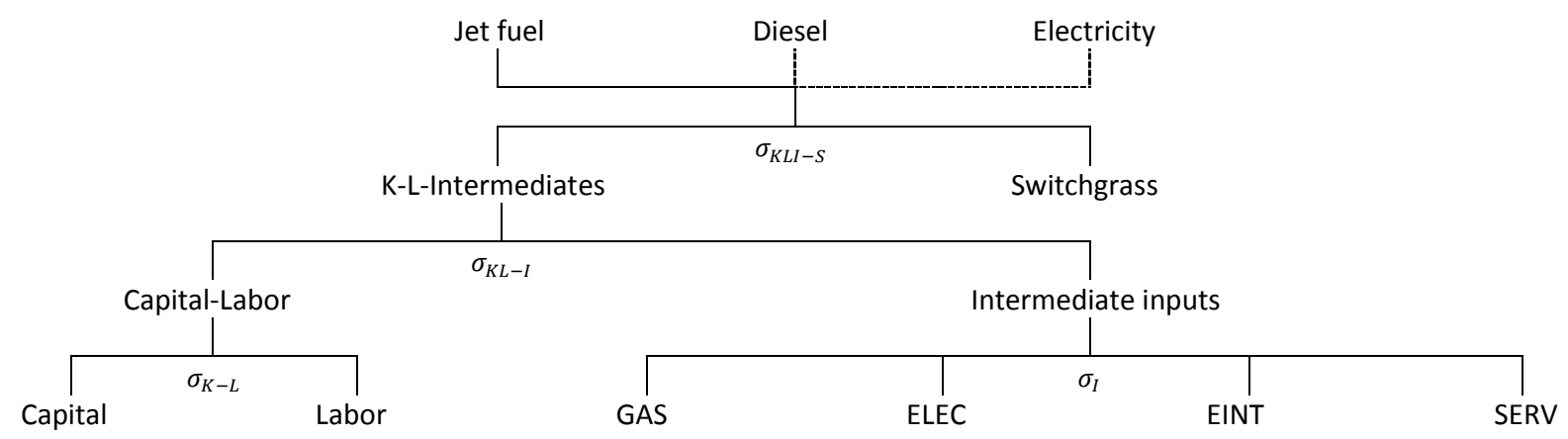

Figure 4. Advanced fermentation production. 
Table 1. Renewable jet fuel policy cases considered in the stylized analysis.

Label Description

Include

Renewable jet fuel goal included in RFS2 mandates

Additional

Renewable jet fuel goal specified as an additional target to RFS2 mandates

Exceed Cellulosic biofuel production exceeds the RFS2 mandate for this fuel 
Table 2. Aggregation in the EPPA-A model.

\begin{tabular}{lll}
\hline Regions & Sectors & Primary inputs \\
\hline United States & Energy sectors & Non-energy resources \\
Canada & Coal & Labor \\
Mexico & Crude oil & Crop land \\
Brazil & Natural gas & Pasture land \\
Latin America & Aviation fuel & Forest land \\
Australia-New Zealand & Other refined oil & Energy resources \\
European Union & Electricity & Crude oil \\
Rest of Europe and C. Asia & & Shale oil \\
Russia & Non-energy sectors & Conventional natural Gas \\
Japan & Crops & Shale gas \\
China & Livestock & Coal \\
East Asia & Forestry & \\
Rest of Asia & Energy-intensive industry & \\
India & Other industry & \\
Africa & Services & \\
Middle East & Air transportation & \\
& Other industrial transportation & \\
& Household transport & \\
\hline
\end{tabular}


Table 3. Revenues, costs and lifecycle emissions for advanced fermentation jet fuel pathways.

\begin{tabular}{|c|c|c|c|c|c|c|}
\hline \multirow[b]{2}{*}{ Cost case: } & \multicolumn{3}{|c|}{ Low-jet product slate } & \multicolumn{3}{|c|}{ High-jet product slate } \\
\hline & Low & Medium & High & Low & Medium & High \\
\hline \multicolumn{7}{|c|}{ Revenue per gallon of jet fuel produced (2010\$) } \\
\hline Jet fuel & 2.71 & 2.71 & 2.71 & 2.71 & 2.71 & 2.71 \\
\hline Other refined oil & 1.59 & 1.59 & 1.59 & - & - & - \\
\hline Electricity & 0.08 & - & - & 0.05 & - & - \\
\hline Total revenue & 4.37 & 4.29 & 4.30 & 2.76 & 2.71 & 2.71 \\
\hline \multicolumn{7}{|c|}{$\begin{array}{l}\text { Costs of total product slate per gallon of jet fuel produced } \\
(2010 \$)\end{array}$} \\
\hline Switchgrass & 1.42 & 2.20 & 3.62 & 0.88 & 1.35 & 2.26 \\
\hline Capital & 3.70 & 7.53 & 15.01 & 2.29 & 4.49 & 9.34 \\
\hline Labor & 0.14 & 0.42 & 0.84 & 0.09 & 0.25 & 0.52 \\
\hline Natural gas & 0.07 & 0.10 & 0.08 & 0.05 & 0.06 & 0.05 \\
\hline Electricity & - & 0.23 & 0.63 & - & 0.14 & 0.39 \\
\hline Energy-int. industry & 1.20 & 1.86 & 3.06 & 0.75 & 1.14 & 1.91 \\
\hline Services & 0.43 & 1.28 & 2.53 & 0.27 & 0.76 & 1.57 \\
\hline Total cost & 6.96 & 13.62 & 25.76 & 4.32 & 8.20 & 16.04 \\
\hline Cost/Revenue & 1.59 & 3.18 & 5.99 & 1.56 & 3.03 & 5.92 \\
\hline $\begin{array}{l}\text { Lifecycle } \mathrm{CO}_{2} \text { e emissions } \\
\left(\mathrm{gCO}_{2} \mathrm{e} / \mathrm{MJ}\right)\end{array}$ & 13.5 & 37.4 & 89.8 & 11.7 & 33.2 & 80.7 \\
\hline
\end{tabular}

Source: Authors' calculations based on estimates from Staples et al. (2014). 
Table 4. Summary of economic outcomes in 2030.

\begin{tabular}{|c|c|c|c|c|c|c|c|c|}
\hline & \multirow[t]{2}{*}{ Reference } & \multirow[t]{2}{*}{ RFS2 } & \multicolumn{2}{|c|}{ Low-cost } & \multicolumn{2}{|c|}{ Medium-cost } & \multicolumn{2}{|c|}{ High-cost } \\
\hline & & & High-jet & Low-jet & High-jet & Low-jet & High-jet & Low-jet \\
\hline \multicolumn{9}{|c|}{ Cellulosic RIN prices and implicit jet fuel subsidies (2010\$/jet-equivalent gallon) } \\
\hline Cellulosic & - & 0.35 & 0.35 & 0.35 & 0.35 & 0.35 & 0.35 & 0.36 \\
\hline Renewable jet & - & & 0.45 & 0.50 & 4.65 & 7.73 & 13.12 & 20.85 \\
\hline \multicolumn{9}{|l|}{ Jet fuel costs and prices (2010\$/gal.) } \\
\hline Renewable jet fuel cost & - & - & 4.01 & 4.05 & 8.21 & 11.30 & 16.68 & 24.41 \\
\hline Renewable jet price & - & - & 3.66 & 3.71 & 7.86 & 10.94 & 16.33 & 24.06 \\
\hline Average jet fuel price & $\$ 3.23$ & $\$ 3.21$ & $\$ 3.22$ & $\$ 3.22$ & $\$ 3.28$ & $\$ 3.32$ & $\$ 3.40$ & $\$ 3.51$ \\
\hline \multicolumn{9}{|l|}{ National metrics } \\
\hline Switchgrass price $(2010 \$ / t)$ & - & $\$ 57.33$ & $\$ 57.33$ & $\$ 57.33$ & $\$ 57.32$ & $\$ 57.32$ & $\$ 57.32$ & $\$ 57.31$ \\
\hline GDP ( $\Delta$ relative to ref.) & - & -0.33 & -0.34 & -0.33 & -0.36 & -0.38 & -0.42 & -0.46 \\
\hline \multicolumn{9}{|l|}{ Aviation metrics } \\
\hline Revenue passenger miles (billion) & 1,347 & 1,342 & 1,341 & 1,341 & 1,331 & 1,324 & 1,311 & 1,294 \\
\hline Fuel consumption (gallons, million) & 25,387 & 25,288 & 25,267 & 25,266 & 25,065 & 24,920 & 24,667 & 24,317 \\
\hline Lifecycle $\mathrm{CO}_{2} \mathrm{e}$ emissions (Mt) & 295.1 & 294.0 & 290.2 & 290.3 & 288.9 & 287.4 & 286.5 & 282.8 \\
\hline
\end{tabular}


Table 5. Proportional reductions in lifecycle $\mathrm{CO}_{2} \mathrm{e}$ emissions and abatement costs.

\begin{tabular}{|c|c|c|c|c|c|c|}
\hline & \multicolumn{2}{|c|}{ Low-cost } & \multicolumn{2}{|c|}{ Medium-cost } & \multicolumn{2}{|c|}{ High-cost } \\
\hline & High-jet & Low-jet & High-jet & Low-jet & High-jet & Low-jet \\
\hline \multicolumn{7}{|c|}{ Proportion reduction in lifecycle $\mathrm{CO}_{2} \mathrm{e}$ emissions relative to the RFS2 scenario } \\
\hline Due to biofuel use & $-1.2 \%$ & $-1.2 \%$ & $-0.9 \%$ & $-0.8 \%$ & $-0.1 \%$ & $0.0 \%$ \\
\hline Due to reduced fuel use & $-0.1 \%$ & $-0.1 \%$ & $-0.9 \%$ & $-1.5 \%$ & $-2.5 \%$ & $-3.8 \%$ \\
\hline Total & $-1.3 \%$ & $-1.3 \%$ & $-1.7 \%$ & $-2.2 \%$ & $-2.6 \%$ & $-3.8 \%$ \\
\hline \multicolumn{7}{|c|}{ Gallons of biofuel consumption required to abate one metric ton of $\mathrm{CO}_{2} \mathrm{e}$} \\
\hline Biofuel per $t$ of abatement & 99.3 & 101.7 & 138.6 & 150.2 & $1,106.8$ & - \\
\hline \multicolumn{7}{|l|}{$\mathrm{CO}_{2} \mathrm{e}$ abatement cost $(2010 \$ / \mathrm{t})$} \\
\hline Direct effect ${ }^{c}$ & $\$ 45.0$ & $\$ 50.6$ & $\$ 645.1$ & $\$ 11,61.8$ & $\$ 14,515.7$ & - \\
\hline Direct and indirect effects ${ }^{d}$ & $\$ 42.1$ & $\$ 47.2$ & $\$ 318.4$ & $\$ 409.5$ & $\$ 609.1$ & $\$ 652.4$ \\
\hline
\end{tabular}

